\title{
Towards the use of remote-sensing data for monitoring of abandoned oil palm lands in Malaysia: a semi-automatic approach
}

\begin{abstract}
Oil palm is a commercial crop that is important for its food value and as a biofuel, along with its other benefits towards the economy and human health. Currently, Malaysia cultivates approximately 5.64 million ha of oil palm. To date, a study identifying abandoned oil palm areas using satellite images is almost non-existent. Conventionally, the monitoring of abandoned oil palm lands is tedious and time consuming, especially over large areas. Hence, in this article, the capability of high resolution satellite image via Satellite Pour I'Observation de la Terre-6 (SPOT-6) products to extract abandoned oil palm areas was explored, as was the use of multi-temporal Landsat Operational Land Imager (OLI) imagery to develop the phenology of abandoned oil palm sites. Homogeneity measures derived through SPOT images played a more important role to identify abandoned oil palm than crop phenology characteristics extracted from high spectral resolution of Landsat images. With the advancement of object-oriented classification, monitoring of abandoned oil palm areas can be done semi-automatically with an accuracy of $92 \pm 1 \%$.
\end{abstract}

Keyword: Oil palm; Malaysia; Remote sensing; Commercial crop 